E3S Web of Conferences 1, 22004 (2013)

DOI: $10.1051 / \mathrm{e} 3$ sconf/20130122004

(C) Owned by the authors, published by EDP Sciences, 2013

\title{
A methodology for Good Environmental Status assessment for mercury in the Mediterranean
}

\author{
S. Cinnirella ${ }^{1}$, M. Graziano ${ }^{1}$ and N. Pirrone ${ }^{2}$ \\ ${ }^{1}$ CNR-Institute of Atmospheric Pollution Research, Division of Rende, Rende, Italy, s.cinnirella@iia.cnr.it \\ ${ }^{2}$ CNR-Institute of Atmospheric Pollution Research, Monterotondo Scalo, Italy
}

\begin{abstract}
This study presents results from an integrated assessment of mercury pollution aimed at characterizing the primary gaps in our knowledge of the monitoring of the Mediterranean Sea. To conduct this study, we compared measurements of mercury in water and biota with the Environmental Quality Standards laid down by the Environmental Quality Standards Directive (2008/105/EC). This methodological approach is based on the DPSWR (Driver-Pressure-State-Welfare change-Response).
\end{abstract}

Key words: Environmental Quality Standards, marine waters, pollutants, heavy metals, polycyclic aromatic hydrocarbons

\section{Introduction}

Marine pollution by hazardous chemical substances like heavy metals is of particular concern for the Mediterranean Sea (Albaiges, 2005; González-Fernández et al., 2010). These contaminants can reach the sea by direct discharge to marine waters, or by rivers, run-off from soil, or atmospheric deposition (Epple et al., 2002, Pirrone et al., 2005; González-Fernández et al., 2011).

The unique ecological and socio-economic features of the Mediterranean region make it particularly susceptible to environmental degradation resulting from a combination of anthropogenic and natural pressures. While the highly industrialized countries on the northwest coast affect the marine environment through industrial and urban emissions, urban wastewater discharges on the southeastern coast are the main problem affecting the sea. These multifaceted pressures make assessing impacts particularly difficult, and they complicate how restoration measures are defined, agreed upon, and ultimately implemented.

In this context, the protection of marine ecosystems requires multidisciplinary and holistic information on all related processes, to consider both their structures and functions (Ojeda et al., 2009). Furthermore, an increasing number of National and International agreements are calling for the development of tools that foster sustainable management of marine environments (e.g. conserving biodiversity and preserving water quality). At the European level, the Marine Strategy Framework Directive 2008/56/EC (MSFD) establishes a framework wherein Member States must take the necessary measures to first achieve and then maintain Good Environmental Status (GEnS) in marine environments by the year 2020. Member States are required to achieve obtain GEnS through the application of by applying an Ecosystem-based Approach (EA) to marine management. The roadmap for implementing the MSFD requires an initial assessment of the marine environment, to both characterize GEnS and identify appropriate environmental targets and associated indicators. This assessment should help in achieving and maintaining GEnS, a status that must be determined on the basis of eleven qualitative descriptors. These descriptors reflect a mixture of environmental and anthropocentric concerns, as they establish criteria and methodological standards for a good environmental status for marine waters, as reported in the Commission Decision of 1 September, 2010 (2010/477/EU).

With the above in mind, we developed a conceptual model for the Mediterranean Region that was based on the connection between pressures exerted on marine ecosystems by human activities and the consequences for human welfare that resulted from these environmental changes. The assessment focused on contaminant pollution and its consequences for Mediterranean marine ecosystems, which has been a key challenge for the implementation of policies relevant to the Mediterranean, including both the Mediterranean Action Plan and the EU Marine Strategy Framework Directive.

This study presents results from an integrated assessment of mercury pollution aimed at characterizing the primary gaps in our knowledge of the monitoring of the Mediterranean Sea. 


\section{Materials and Methods}

The methodological approach for this assessment was based on the DPSWR framework (Driver-Pressure-State-Welfare change-Response) (Cooper, 2012). We utilized this framework for its:

- Selection of issues with reference to chemical pollution;

- Development of the cause-effect conceptual model for the selected issues;

- Definition of the indicators list;

- Assessment of Pressures and characterization of environmental State for the Mediterranean Sea and its basin;

- Definition of Good Environmental Status (GEnS) for the Mediterranean Sea;

- Assessment of Welfare by considering the benefits affected.

The contaminants selected also followed the recommendations outlined in Directive 2008/105/EC on Environmental Quality Standards (EQSD) that establishes limits on concentrations for 33 substances of priority and 8 other pollutants in surface waters.

The DPSWR framework applied a number of important factors to the Mediterranean, included urbanization, tourism, shipping, and industry. These factors have been a driving force of environmental change and have caused a number of Pressures on the marine environment, including changes in land-use, the dumping of solid waste, and chemical pollution by a number of substances (including heavy metals, hydrocarbons, and surfactant / chelating agents) (UNEP/MAP, 2009; EEA, 2006).

\section{Results and Discussion}

To assess the environmental status of marine waters and biota with respect to mercury contamination, we considered atmospheric deposition and riverine input as the main sources of additional mercury to natural background levels already present in marine waters (Krabbenhoft and Schuster, 2002; Mason, 2005; Pirrone and Mahaffey, 2005). Wet deposition accounts for about two thirds of the overall mercury budget entering the marine system, with the other third coming from dry deposition (Pirrone et al. 1995; Petersen et al. 1998; Schroeder et al. 1998).

The atmospheric input of mercury in the Mediterranean is influenced by where air masses originate. Primarily it is either winds from the northern, industrialized parts of Europe or those from the southern Sahara that transport metals in aerosol form (Guieu et al., 1997). The modeled average deposition for 1995, 2000 and 2005 was 1.74, 1.52, $1.64 \mathrm{Mg}$, respectively (EMEP, Travnikov, personal communication), which had differing impacts over Mediterranean marine eco-regions, as shown in Figure 1.

The MAP estimates that riverine discharges to the Mediterranean are the largest source of mercury $(92 \mathrm{Mg}$ $y-1)$, though direct industrial discharges from the coastal zone are also significant (around 30\% of total).

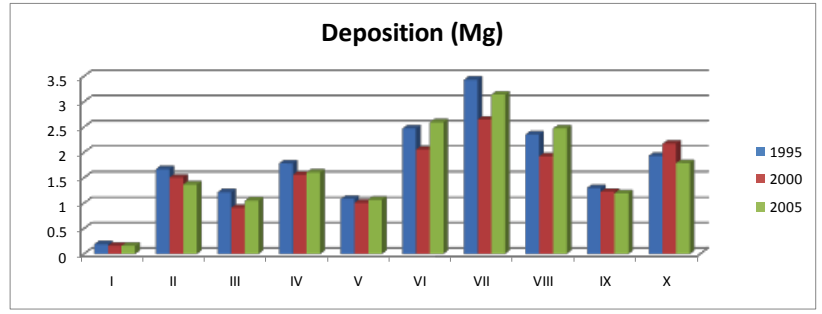

Fig. 1. Mercury deposition in Mediterranean ecoregions for 1995, 2000 and 2005 (courtesy of Travnikov (EMEP), 2011). Ecoregions: I, Alboran; II, North-Western; III, South-Western; IV, Tyrrhenian; V Adriatic; VI, Ionian; VII, Central; VIII, Aegean; IX, North-Levantine; X, South-Levantine; XI, Marmara.

A regional analysis of several cruise campaigns (i.e. MEDOCEANOR) showed that dissolved gaseous mercury (DGM) was different in the western and eastern Mediterranean (Figure 2a). In addition, we also found differences for methylmercury, despite it being less-vigorously monitored (Figure 2b).

a)

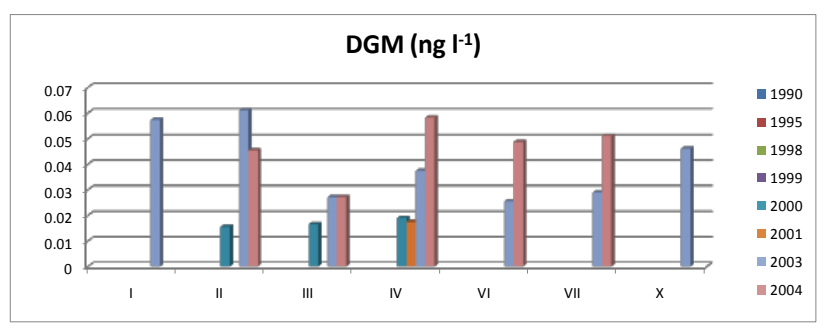

b)

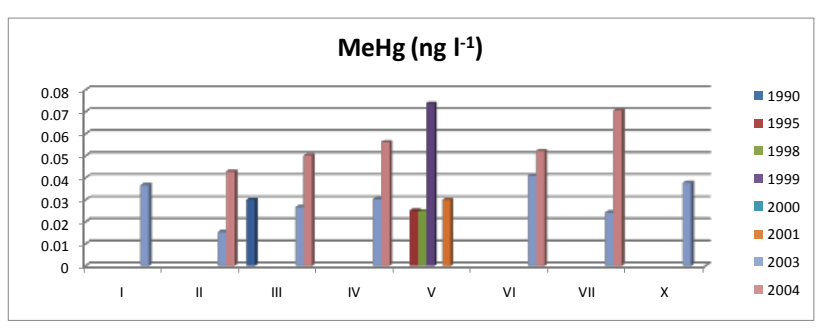

Fig. 2. Dissolved gaseous mercury a) and methylmercury b) concentrations in Mediterranean ecoregions

To see that "Concentrations of contaminants are at levels not giving rise to pollution effects" under the MSFD, Task Group 8 recommends using three core data assessment elements (Law et al., 2010). These assess if:

- Concentrations of contaminants in water, sediment and/or biota are below environmental target levels identified on the basis of eco-toxicological data;

- $\quad$ Pollution effect levels are below environmental target levels representing harm at the organism, population, community, and ecosystem levels; 
- Concentrations of contaminants in water, sediment, and/or biota, and the occurrence and severity of their pollution effects, should not be increasing.

With the above in mind, data should be interpreted against environmental target levels that are safe for humans and the environment. In particular, either Environmental Quality Standards (EQSs), which represent thresholds that should not be exceeded, or Environmental Assessment Criteria (EACs), which are long-term objectives for concentrations close to background, can be adopted as suitable target levels.

The Environmental Quality Standards Directive (2008/105/EC) denotes EQSs for priority substances and certain other pollutants. Two kinds of EQSs were established to cover both long-term and short-term chemical effects:

i. the annual average concentration (AA-EQS), referring to the annual arithmetic mean concentration, providing protection against chronic exposure, and

ii. the maximum acceptable concentration (MAC-EQS) for protection against acute toxic effects caused by short-term contaminant peaks, not to be exceeded at any time.

On the other side, OSPAR has used two forms of assessment criteria in the interpretation of chemical monitoring data:

i. background concentrations (BCs) and associated Background Assessment Concentrations (BACs);

ii. Environmental Assessment Criteria (EACs).

$\mathrm{BC}$ are background contaminant concentrations at a "pristine" or "remote" site, based on contemporary or historical data. While BACs are mathematically derived from BCs to make precautionary tests of whether observed concentrations are near background levels (OSPAR, 2008), EACs are contaminant concentrations in monitoring matrices, normally sediment or biota, below which unintended/unacceptable biological responses (or unintended/unacceptable levels of such responses) are unlikely to occur.

Finally, the US EPA has developed Effects Range values (ER values) to be used in assessing both the quality of coastal and estuarine environments and the ecological significance of hazardous substance concentrations found in sediments. ER values are calculated from by collating large amounts of information on contaminant concentrations in the sediments where biological effects were found. Two main assessment criteria have been calculated:

- $\quad$ ER-Low (ERL), defined as the lower tenth percentile of the sediment concentrations dataset associated with any particular biological effect;

- ER-Median (ERM), defined as the median of concentrations associated with any particular biological effect.

EACs are available for a wide range of contaminants, but, unfortunately, not for metals (Law et al., 2010). Consequently, we required an alternative approach to assessing these transition points, one that needed to be coherent across the range of species addressed in the Co-ordinated Environmental Monitoring Programme (OSPAR, 2008). Two possible approaches were considered by Law et al. (2010):

- $\quad$ an added risk approach, which requires using the sum of the proposed BCs and EACs, to derive a maximum permissible concentration (MPC).

- an assessment of the contaminant concentrations in fish and shellfish, with respect to their human health risk as set by the Commission Regulation No. 1881/2006 (and subsequent additions and amendments).

Hence, we adopted the transition points $\mathrm{T} 0$ and $\mathrm{T} 1$ for both mercury and PAHs in sediments and biota. These are plotted with the measurements in Figure 3.

The results demonstrate that several cases are above the maximum levels in all media. The worst condition was for sediments, which had $72 \%$ of values above ERL, followed by mercury in fish, which had $24 \%$ of its values above EC. While mercury concentration in water had $16 \%$ of its cases above MAC-EQS, mussels fared much better, with only $0.5 \%$ cases over the EC.

\section{Conclusion}

To achieve a GEnS for the Mediterranean, Member States must develop:

a. an assessment of pressures and threats impacting the marine environment

b. a list of regional environmental objectives, indicators, and monitoring measures for evaluating the progress made towards achieving these objectives.

With regard to assessment, implementing the EQS Directive will help create an assessment of contaminants, as contaminant target levels have already been established.

But there still exists one major weakness: any determination of environmental concern will be limited by a lack of relevant assessment tools.

The adopted "thresholds" have been derived from OSPAR 2008, but neither the assessments of concentrations, where no deterioration of the environment can be expected (at "pristine" or "remote" sites (T0)), nor the assessments of concentrations where significant adverse effects to the environment (T1), have been "calibrated" for the Mediterranean.

In addition, an improved understanding of ecosystem functioning is required, especially with regard to the definition of GEnS. Even when they can be identified, it is still necessary to understand the extent to which impacts can affect ecosystem functioning. This is fundamental to knowing how various impacts can alter an ecosystem's services, and thus the costs associated with their degradation.

Additional research is needed to define environmental targets (i.e. a set value for a particular environmental 
a)

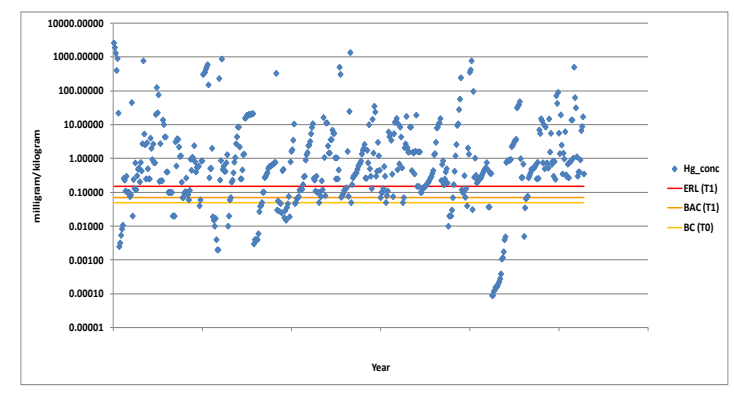

c)

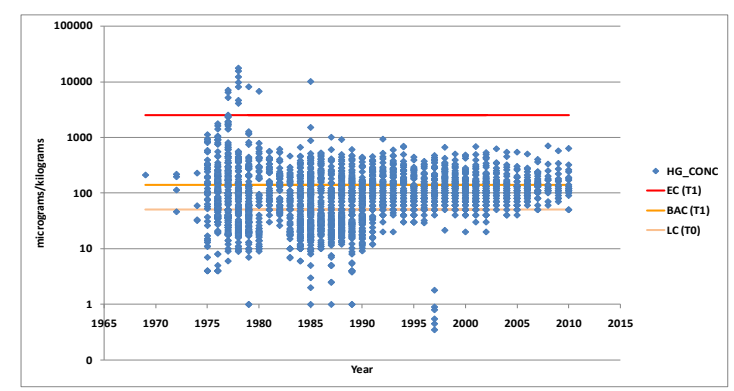

b)

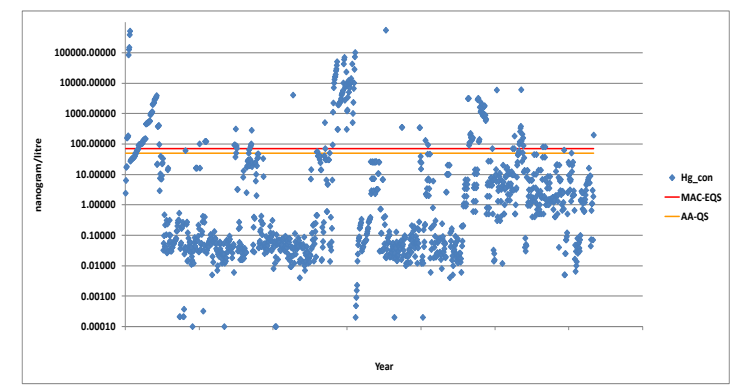

d)

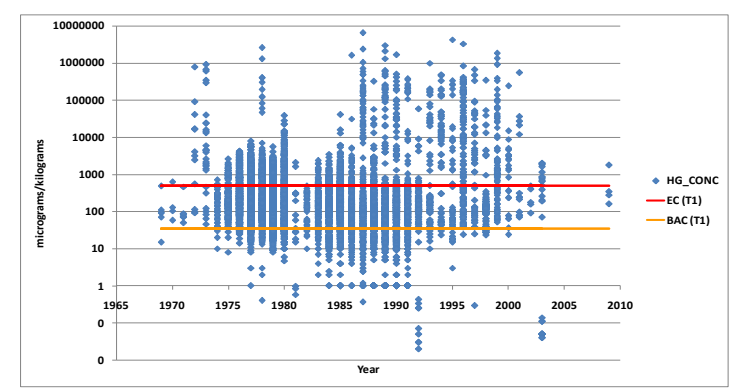

Fig. 3. Total mercury concentration in sediments a), water b), mussels c) and fish d) compared to transition points

indicator or index, set at or beyond the GEnS level). For instance for Descriptors 8 and 9 , it is necessary to establish threshold values for key contaminants. These values distinguish between environmental conditions that are acceptable (with little or no risk) or unacceptable (with higher risk). In the Mediterranean Region, threshold values for major hazardous contaminants like trace metals, chlorinated compounds (pesticides and PCBs), and PAHs are lacking or undefined. Also, the details of the relationship between sediment contaminant levels and the marine food chain have yet to be fully explored.

Moreover, monitoring contaminants in the food chain continues to be of utmost importance for compounds that are prone to bioaccumulation and biomagnification. Our analysis of measurements already reported in multiple databases (and present in existing scientific literature) shows that assessing bioaccumulation can be extremely difficult, due to a widespread lack of information about the compounds that comprise the food chain. This is particularly true for heavy metals, as they tend to accumulate within the food chain and can be stored in soft (e.g., kidney) and hard body tissues (e.g., bone). Therefore, its important to note that we can improve our understanding of bioaccumulation processes with focused measurements and monitoring of marine species that are part of the same food chain, and by taking their Trophic Levels into account.

\section{Acknowledgements}

The authors thank the financial supports of KnowSeas project (grant number 226675).

\section{References}

Albaiges J. 2005. Persistent organic pollutants in the Mediterranean Sea. In: The Handbook of Environmental Chemistry, Vol.5, part K (Ed. A. Saliot). Springer, Heidelber, Germany, pp. 1-61

Cooper P., 2012. The DPSWR Social-Ecological Accounting Framework: Notes on its Definition and Application. Policy Brief No. 3. EU FP7 KNOWSEAS Project. ISBN 0-9529089-5-6.

EEA, 2006. Priority issues in the Mediterranean environment. Environmental Issues Series No. 4. Luxembourg: European Communities

González-Fernández D., Garrido-Pérez M.C., Nebot-Sanz E., Sales-Márquez D., 2011. Source and Fate of Heavy Metals in Marine Sediments from a Semi-Enclosed Deep Embayment Subjected to Severe Anthropogenic Activities - Water Air Soil Pollut, 221:191-202.

Guieu C., Chester R., Nimmo M., Martin J.-M., Guerzoni S., Nicolas E., Mateu J., Keyse S., 1997. Atmospheric input of dissolved and particulate metals to the northwestern Mediterranean. Deep Sea Research Part II: Topical Studies in Oceanography, 44 (3-4): 655-674.

Krabbenhoft D., Schuster P., 2002. Glacial Ice Cores Reveal a Record of Natural and Anthropogenic Atmospheric Mercury Deposition for the Last 270 Years. USGS Fact Sheet FS-051-02.

Law R., Hanke G., Angelidis M., Batty J., Bignert A., Dachs J., Davies I., Denga Y., Duffek A., Herut B., Hylland K., Lepom P., Leonards P., Mehtonen J., 
Piha H., Roose P., Tronczynski J., Velikova V., Vethaak D., 2010. Marine Strategy Framework Directive, Task Group 8 Report, Contaminants and pollution effects. (Piha H., Editor). EUR - Scientific and Technical Research series, JRC and ICES.

Mason R. P., Gill G. A., 2005. Mercury in the marine Environment, in: Parsons, M. B., Per-cival, J. B. (Eds.), Mineralogical Association of Canada Short Course 34, Mercury : Sources, Measurements, Cycles and Effects, Halifax, Chapter 10 pp 179-216

Ojeda-Martínez C., Giménez Casalduero F., Bayle-Sempere J.T., Barbera Cebrián C., Valle C., Sanchez-Lizaso J.L., Forcada A., Sanchez-Jerez P., Martín-Sosa P., Falcón J.M., Salas F., Graziano M., Chemello R., Stobart B., Cartagena P., Pérez-Ruzafa A., Vandeperre F., Rochel E., Planes S., Brito A., 2009. A conceptual framework for the integral management of marine protected areas. Ocean and Coastal Management, 52 (2):89-101.

OSPAR Commission, 2008. Co-ordinated Environmental Monitoring Programme Assessment Manual for contaminants in sediment and biota. Publication No. $379 / 2008$.

Petersen G., Iverfeldt A., Munthe J., 1998. Atmospheric mercury species over central and northern Europe. Model calculations and comparison with observations from the Nordic Air and Precipitation Network for 1987 and 1988. Atmos. Environ., 29, 47-67.

Pirrone N., Glinsorn G., Keeler G.J., 1995. Ambient Levels and Dry Deposition Fluxes of Mercury to Lakes Huron, Erie and St. Clair. Water, Air Soil Pollut., 80, 179-188.

Pirrone N., Mahaffey K., 2005. Dynamics of Mercury Pollution on Regional and Global Scales. Springer Verlag Publishers, Norwell, MA, USA.

Pirrone N., Sprovieri S., Hedgecock I., Trunfio A., Cinnirella S., 2005a. Dynamic Processes of Atmospheric Mercury in the Mediterranean Region. In: Dynamics of Mercury Pollution on Regional and Global Scales. Atmospheric Processes, Human Health and Policy, (Pirrone and Mahaffey Eds.), Springer Verlag Publishers, Norwell, MA, USA: 541-579.

Schroeder, W.H., Munthe, J., Lindqvist, O., 1998. Cycling of Mercury between Water, Air, and Soil Compartments of the Environment. Water, Air, Soil Pollut., 48, 337-347.

UNEP/MAP, 2009. State of the environment and development in the Mediterranean. UNEP/MAP, Athens. 